\title{
Gender Preference in Current Pregnancy among Primigravidae
}

\author{
Thapa M, Bajracharya J \\ ${ }^{1}$ Kathmandu Medical College, Kathmandu.
}

Received: 3-Feb-2017; Accepted: 18-May-2017

\begin{abstract}
Aims: To study preference of gender of fetuses in present pregnancy, wish of number of children in the family, and knowledge of pre-natal sex selection by the pregnant women, and to study the impact of education level of women on preference of fetal gender and the desire of women to know the gender of fetuses.
\end{abstract}

Methods: It was a descriptive study done in Obstetrics and Gynaecology Department of Kathmandu Medical College. All primigravidae, who did not know the gender of their fetuses and willing to participate in the study were enrolled in the study. The pregnant women were interviewed regarding demographic profile of the women, choice of gender of fetuses, number of children they want to have and knowledge regarding prenatal sex selection, using semi structured questionnaire.

Results: Two hundred women were studied. Two third of them were educated minimum of 12 th Class. Most of the pregnant women $(81 \%)$ did not show preference of gender of their fetuses, only $13 \%$ of them wanted to have son in this pregnancy. About $61 \%$ of them want to have two children in their family. Regarding prenatal sex selection, only $44 \%$ knew about it. More than half $(56 \%)$ of the women showed interest in knowing the gender of fetuses in present pregnancy. The education status of women did not have an effect on the choice of either gender or wish to know the gender of unborn fetuses by primigravidae.

Conclusions: Most of the primigravidae had no choice of gender of fetuses. Two children in the family was regarded as ideal by most of the women

Keywords: education status, gender preference, prenatal sex selection

DOI: http://dx.doi.org/10.3126/njog.v12i1.18979

\section{INTRODUCTION}

Nepal is largelya patriarchal society; males are considered to be the heads of society and the family. Females, conversely, are viewed as subordinate to them. Females are economically, socially and culturally dependant on their male partners. Sons, too, are regarded as the person to continue the family name.As a result, many Nepalese families prefer to have a male baby to be born in their family, which is evidenced by the studies from our country. The sex ratio in Nepal is 0.96:1 (male: female). ${ }^{1-4}$

Preferences of the gender of the baby to be born by the pregnant women are entirely personal. The pregnant women expressed no preference or preference of one of the gender of their fetuses were seen in various studies. ${ }^{5-7}$

The studies from western countriesshowed preference of the pregnant women to have a girl, ${ }^{8}$ and men's desire to have a son as their first child. ${ }^{9}$

\section{CORRESPONDENCE}

Dr MeenaThapa,

Kathmandu Medical College,

Sinamangal, Kathmandu

Phone +977-9851060052,

Email: meenathapa513@hotmail.com
The level of education of women has also changed their role in society. It is found that the education status of women plays a role in making a choice of the gender of the fetus during a current pregnancy. ${ }^{10}$

Though the desire of number of children in the family is different in different countries, the desired number of children has reduced over the years. ${ }^{11}$ Most pregnant women wish to know the gender of their fetuses ${ }^{12,13}$, but awareness of the methods of determination of prenatal sex of the fetuses is also high in different communities. ${ }^{5,14}$

This study was done to find out the gender preference of pregnant women for their first baby, the number of children they want to have, their knowledge of prenatal sex determination, wish to know the gender of the unborn fetus, and the impact of education levels of the women on both their preference of gender and desire to know the gender of unborn fetuses.

\section{METHODS}

A hospital based cross sectional, descriptive study was conducted. It was done over the period of 8 months from January to August 2016. This study was conducted in OPD of Gynaecology and Obstetrics 
Department of Kathmandu Medical College, Kathmandu. The study was performed by interview using a semi structured questionnaire. Pregnant women who came for antenatal checkup andwere pregnant by the first time were taken in the study. Those who knew the sex of their fetuses in-utero were excluded from the study.

This study was done after obtaining ethical clearance from the Ethical and institutional review board of Kathmandu Medical College.

The verbal consent was taken from all eligible women prior to enrollment in the study. Then they were interviewed regarding their demographic profile, choice of sex of their unborn baby, knowledge regarding prenatal sex determination and their desired number of children they want to have.

The data were recorded in an Excel spreadsheet and analyzed using SPSS 16. A chi-square test was used to calculate the level of significance of the data.

\section{RESULTS}

There were 200 primigravidae in the study. The mean age of pregnant women was $25 \pm 3.750$ years,ranging from 16 to 35 years. The majority of pregnant women $(64.5 \%)$ belonged to higher castes i.e Brahmin and Chhetri. Only $1 \%$ of participants were Muslim.

About $75 \%$ of the pregnant women interviewed were educated at a minimum of $12^{\text {th }}$ class. Illiterate women were few $(5 \%)$ in this study(Table 1$)$.
Table 1: Education status of pregnant women

\begin{tabular}{|lll|}
\hline Education status & $\begin{array}{l}\text { Number of } \\
\text { Women }(\mathbf{N}=\mathbf{2 0 0})\end{array}$ & Percentage \\
\hline Illiterate & 10 & $5 \%$ \\
Literate/up to SLC & 39 & $19.5 \%$ \\
Up to $12^{\text {th }}$ Pass & 89 & $44.5 \%$ \\
Graduate/Above & 62 & $31 \%$ \\
\hline
\end{tabular}

The majority (82\%)of pregnant women did not express preference of gender of their unborn baby in present pregnancy. Few pregnant women wanted to bear a son $(13.5 \%)$ and very few women wanted to have female child, as a first child (Table 2). The association between gender preference and education status of the women was not found in this study. But surprisingly, no preference of girl child was demonstrated by illiterate women(Table 3 ).

Table 2: Preference of gender in present pregnancy

\begin{tabular}{|lll|}
\hline $\begin{array}{l}\text { Gender } \\
\text { preference }\end{array}$ & $\begin{array}{l}\text { Number of women } \\
(\mathbf{N}=\mathbf{2 0 0})\end{array}$ & Percentage \\
\hline Male & 27 & 13.5 \\
Female & 8 & 4 \\
Any & 165 & 82.5 \\
\hline
\end{tabular}

Among the studied pregnant women, more than half $(56 \%)$ didnot want to know the gender of their unborn babies. However, no relationship was seen between the education status of the women and wish of the pregnant women to know the sex of the unborn fetuses in present pregnancy (Table 4).

Table 3: Education status of women and gender preference

\begin{tabular}{|llllllll|}
\hline Education status of pregnant & Male & & Female & & Any & Total & p-value \\
\hline Illiterate & 2 & 20 & - & 2.56 & 8 & 80 & 10 \\
Up to SLC & 9 & 223.07 & 1 & 4.49 & 29 & 74.3 & 39 \\
Up to 12 ${ }^{\text {th }}$ class & 11 & 12.35 & 4 & 4.83 & 74 & 83.14 & 89 \\
Graduate/Above & 5 & 8.66 & 3 & & 54 & 87.9 & 62 \\
Total & 27 & & 8 & & 165 & 200 \\
\hline
\end{tabular}

Table 4: Knowledge regarding pre natal sex determination by education status

\begin{tabular}{|c|c|c|c|c|}
\hline \multirow{2}{*}{$\begin{array}{l}\text { Education statusof } \\
\text { Pregnant }\end{array}$} & \multicolumn{2}{|c|}{ Knowledge regarding Prenatal sex Determination (N-200) } & \multirow[t]{2}{*}{ Total } & \multirow[t]{2}{*}{ p-value } \\
\hline & Yes & No & & \\
\hline Illiterate & 3 & 7 & 10 & \multirow{5}{*}{0.670} \\
\hline Up to SLC pass & 19 & 20 & 39 & \\
\hline Upto 12th Pass & 37 & 52 & 89 & \\
\hline Graduate /Above & 29 & 33 & 62 & \\
\hline Total & 88 & 112 & 200 & \\
\hline
\end{tabular}

Among the pregnant women, $44 \%$ of them knew about prenatal sex determination. About $52.2 \%$ of woman who knew the sex determination methods had shown interest to know the gender of their unborn babies in present pregnancy. Likewise, $39.2 \%$ of women who were not aware of the prenatal sex determination also wanted to know the gender of fetus in current pregnancy. 
Out of 200 pregnant women, about $61 \%$ had planned to have two children, whereas $36.5 \%$ of women wanted to have only one child in their family. However, very few (1.5\%) women wanted to have more than two children and one woman did not give her view on it.

\section{DISCUSSION}

According to National Demography and Health Survey 2011, the median age of women at first birth in Nepal is 20.1 years. ${ }^{15}$ The mean age of pregnant women in our study is found to be more than the national record. This could be due to our study being done in an urban setting where age at marriage is higher than the national record.

According to National census $2011^{1}$,among the people, Chhetri and Brahmin accounts for $28.8 \%$, but we found that around two-thirds of women in our study belonged to Chhetri and Brahmin

The literacy rate of adult women in Nepal is only $42.5 \%{ }^{1}$ The literate and educated women numbered significantly more in our study. Similarly, the education status of women was found to be less than our study, in study by Vadera BN. ${ }^{7}$ It could be due to our study being conducted almost 10 years later than that study; moreover, this study was done in the hospital situated in a big city.

Gender preference was not shown by $82.5 \%$ of women in our study. Similarly, two-thirds of pregnan two men in study done by $\mathrm{Kansal}^{6}$ did not show the gender preference in their study. A study from South India had found that young and educated pregnant women did not show a gender preference of their unborn babies. ${ }^{10} \mathrm{We}$ found that only $13.5 \%$ women had shown the male preference as a first child. Similar findings were found by Sukar- Uddin ${ }^{16}$ in their study. Likewise, Kansal ${ }^{6}$ had found that $22.2 \%$ of women wished to have male in current pregnancy. But much higher rates of male preference were found by Vadera ${ }^{7}$ $(58.5 \%)$ Oleke $^{13}(62 \%)$ and Ohaqwu ${ }^{14}(62 \%)$ in their studies. A study from eastern rural area of Nepal, which was done among the non-pregnant women found that $64.4 \%$ of them wished to have a son as a first child. ${ }^{16}$ There is paucity of studies of gender preference among pregnant women in our country. However, a study by Uprety ${ }^{4}$ showed that males were preferred in the family. Desire to have a son in the family was also seen in the study done among the men of Nepal and Vietnam. ${ }^{2}$ Less preference of males and higher rate of not showing gender preference by pregnant women in our study may be due to us having more literate and educated women. We did not found relationship between education status of women and preference of gender of fetuses, contrary to our finding Yasmin $^{16}$ from eastern India had found that women of lower education status had more preference of gender of fetuses.

We found that $44 \%$ of pregnant women wanted to know the sex of fetus in present pregnancy. The study done by Shukar - Uddins ${ }^{17}$ found that only $31.5 \%$ of women wanted to know the sex of the unborn baby. About $34.7 \%$ of pregnant women wanted to know the gender of their fetuses from eastern India. ${ }^{16}$ But a much higher percentage of pregnant women from Africa desired to know the gender of their unborn babies. ninty four percent of women from Sokoto Nigeria $^{12}, 90 \%$ of primigravidae in Enugu Nigeria ${ }^{13}$ and $61 \%$ pregnant Igbo women ${ }^{14}$ wished to know the gender of their unborn fetuses in present pregnancy.

We found that $44 \%$ of primigravidae were aware of prenatal sex determination method. But $88.4 \%$ of pregnant Igbo women and $84.7 \%$ of Indian women ${ }^{6}$ were aware of it. Another study by Vedpathak ${ }^{5}$ found that $59.9 \%$ of pregnant women were aware of prenatal sex determination methods.

Sixty one percentage of women in our study thought that the ideal number of children wastwo. Seventy percent of pregnant from coastal South India ${ }^{10} 62.8 \%$ of pregnant women from West Bangal ${ }^{18}$ and $88.7 \%$ non-pregnant womenfrom rural area of eastern Nepal ${ }^{19}$ also thought that two children in the family is ideal. Moreover, they also thought that having one son and one daughter is the perfect one.

\section{CONCLUSIONS}

The first time pregnant women did not show preference of gender of their unborn babies. Most of the pregnant women wished to have two children in their families. Nearly half of the pregnant women had knowledge regarding pre natal sex selection. The relationship between gender preference and prenatal sex selection with education status of women was not found in our study. 


\section{REFERENCES}

1. Population Monograph of Nepal. Kathmandu: Government of Nepal, National Planning commission secretariat Central Bureau of Statistics; 2014

2. Nanda P. Study on Gender, Masculinityand son preference in Nepal and Vietnam.New Delhi: International Center for Research on Women. 2012

3. Karki YB. Son preference and the value of sons and daughters in Nepal. Stud Fam Plann. 1988;19(3):169-78

4. Uprety S, Jha N, Poudel IS, Pokhrel PK, Poudel M, Nirou SR. Impact and determinants of gender preferencein Duvavi VDC of eastern Nepal. J Nepal Med Assoc. 2011;51(81):2833

5. VedpathakV, Kakerni V, Nagaonkar A, Deo D, Dahire P, Kawalkar U. Gender preference and awareness regarding sex determinationamong pregnant women- A Hospital based study. Int J Med Sci Public Health. 2013;2(4):1054-7 Doi: 10.5455/ijmsph2013.270820132

6. Kansal R, Khan AM, Bansal R, Parashar P. A hospital-based study on knowledge, attitude and practice of pregnant women on gender preference, prenatal sex determinationand female feticide. Indian J Public Health. 2010;54(4):209-12

7. Vadera BN, Joshi UK, Undakat S, Yadav BS, Yadav S. Study on knowledge, attitudeand practices regarding gender preference and female feticide among pregnant women.Indian J Community Med. 2007; 32:300-1

8. Iserie E, Ozbas AA, Gurhan N, Sari B. Preferences for sex of first born child among primiparous Turkish women. Psychological Reports. Psychol Rep. 2012;111(1):165-72

9. Marleau JD, Saucier JF. Gender Preferences for children Revisited: New Evidence from Germany. J Biosocsci 2002;34(1):13-27

10. Kumar N. Gender preferences among antenatal women: a cross sectional study from Coastal South India. Afr Health Sci.. 2015;15(2):560-7
11. Westoff CF. Desired number of children 2000-2008 DHS Comparative report.USAID, Office of Population Research, Princeton University. 2010 FebReport No.25

12. Maaji SM, Ekela BF, Bello SO, Morhason IO. Do women want disclosure of fetal gender during pre natal ultrasound scan? Ann Afr Med. 2010;9(1)10-4 doi-104103/1596 -3519.62618

13. Oleke TC, Enwereji JO, Okoro OS, Iferikiqwe ES, Ikeako LC, Ezenyeaku CC, et al. Desire for prenatal gender disclosure among primigravida in Enugu Nigeria. Patient Preference and Adherence. 2015;9:429-33

14. Ohaqwu C, Eze C, Eze J, Odo M, Abu. Perception of Male gender preference among Pregnant Igbo Women. Ann Med Health Sci Res. 2014;4(2):173-8

15. Ministry of Health and population (Nepal), New ERA and ICF International INC. Nepal Demographic and Health survey 2011. Kathmandu, Nepal. Ministry of Health and population (Nepal), New ERA and ICF International. 2012

16. Sukar-Uddin S, Ubaid OF, Shahani E, Saleha F. Reasons for disclosure of gender to pregnant women during prenantlultrasonography. Int J Women's Health. 2013;5:781-5

17. Yasmin S, Mukharjee A, Manna N,Baur B, Dutta M, Sau M, Roy M.Gender preference and awereness regarding sex determination among antenatal mothers attending a medical college of eastern India. Scand J Public Health. 2013;41(4):344-6

18. Day I, Chaudhari RN. Gender Preference and its implication, Reproductive behaviour of mothers in rural area of West Bangal. Indian J Community Med. 2009;34(1):66-7

19. Rai P, Sharma IP, Ghimire A, Pokhrel PK, Rijal R, Niraula SR. Effect of gender preference on fertility:cross sectional study among women of Tharu community from rural area of eastern regin of Nepal. Reprod Health. 2014;11:11-5 